\title{
Vitamin D and Cardiometabolic Disease: From Observation to Intervention
}

\author{
Yiqing Song $\cdot$ Lu Wang
}

Published online: 22 March 2012

(C) Springer Science+Business Media, LLC 2012

\begin{abstract}
Vitamin D deficiency has become a major public health problem worldwide due to its increasing prevalence and potential health risks. There is growing evidence from experimental studies to suggest that vitamin D may influence risk of cardiometabolic disease through multiple pathways, including inhibition of the release of proinflammatory cytokines; regulation of the renin-angiotensin system; and favorable effects on lipids, blood pressure, insulin secretion and action, and thrombosis. Human observational data, primarily from cross-sectional studies, have shown that low dietary vitamin D intake or vitamin D levels are inversely related to various cardiometabolic risk factors. Prospective studies have suggested the relationship between low $25(\mathrm{OH})$ $\mathrm{D}$ and increased risk of cardiometabolic disease, including hypertension, type 2 diabetes, and cardiovascular disease. Evidence from small randomized trials and post-hoc analyses of large clinical trials for the effect of vitamin D supplements on cardiometabolic risk factors, however, remains inconsistent. This article aims to summarize epidemiologic data on the relationship between vitamin $\mathrm{D}$ and major cardiometabolic disease and highlight the challenges in translating observational evidence to future intervention studies.
\end{abstract}

Keywords Vitamin D 25 -hydroxyvitamin D (25[OH]D) . Cardiometabolic disease $\cdot$ Cardiometabolic risk factors .

Adiposity $\cdot$ Blood pressure $\cdot$ Insulin secretion and sensitivity Systemic inflammation $\cdot$ Metabolic syndrome $\cdot$ Renin-angiotensin system (RAS) .

Hypertension · Type 2 diabetes .

\footnotetext{
Y. Song $(\triangle) \cdot$ L. Wang

Division of Preventive Medicine, Brigham and Women's Hospital, Harvard Medical School,

900 Commonwealth Avenue East,

Boston, MA 02215, USA

e-mail: ysong3@rics.bwh.harvard.edu
}

Cardiovascular disease · Observational study $\cdot$ Randomized clinical trials · Supplementation

\section{Introduction}

Vitamin D is well-known for its essential role in calcium homeostasis and bone metabolism. However, a large body of evidence from observational and experimental studies has clearly suggested its other physiologic effects, especially those on individual or combined cardiometabolic parameters such as adiposity, blood pressure (BP), lipid and glucose metabolism, and insulin secretion [1-3]. Vitamin D can be obtained from diet, supplements, and conversion of 7 dehydrocholesterol in the skin by UVB radiation [1]. Vitamin $\mathrm{D}$ is hydroxylated in the liver to 25 -hydroxyvitamin $\mathrm{D}$ $(25[\mathrm{OH}] \mathrm{D})$, the major circulating vitamin D metabolite [1]. $25(\mathrm{OH}) \mathrm{D}$ is further metabolized by $1 \alpha$-hydroxylase to 1,25 dihydroxyvitamin $\mathrm{D}\left(1,25[\mathrm{OH}]_{2} \mathrm{D}\right)$, the metabolically active form $[1,2]$. Circulating $25(\mathrm{OH}) \mathrm{D}$, which reflects most sources of vitamin D exposure and has a half-life of 2 to 3 weeks, has been widely used as a reliable surrogate of vitamin $\mathrm{D}$ status $[1,2] .1,25(\mathrm{OH})_{2} \mathrm{D}$ binds to vitamin $\mathrm{D}$ receptors (VDRs), which can be found in more than 30 cell types, including intestinal cells, muscle cells, osteoblasts, parathyroid cells, epidermal cells, vascular endothelial cells, neurons, immune cells, and pancreatic $\beta$ cells [1]. VDR acts as a transcription factor to regulate the rate of gene transcription in many cell types throughout the body.

Vitamin D status is determined by many factors, such as age, sex, race/skin pigmentation, season, geographic latitude, food and supplemental sources of vitamin D, adiposity, and genetic predisposition. A major source of vitamin D is the skin's synthesis of vitamin D3 from sunlight. Biological evidence indicates that melanin in the skin blocks the 
conversion of 7-dehydrocholesterol by UVB rays, thereby limiting vitamin D3 biosynthesis [4]. Observational studies have shown that African Americans have lower circulating levels of $25(\mathrm{OH}) \mathrm{D}$ and are more likely to be vitamin D deficient than those in other ethnic groups [4-6]. Low vitamin D status is also common in many Asian countries and the Middle East, indicating that culture, dress, or the geographical latitude limiting sun exposure may be important contributors [1]. In addition, aging may decrease the ability of skin to produce the necessary precursors for vitamin D synthesis [7]. Also, lack of sun exposure or consuming diets poor in vitamin D may increase the risk of vitamin D deficiency in older adults.

Due to the paucity of data and differences in assay methods, there is no consensus on the cutoff values of 25 $(\mathrm{OH}) \mathrm{D}$ defining vitamin D insufficiency or deficiency. During 2001 to 2004, only $23 \%$ of US adolescents and adults had serum $25(\mathrm{OH}) \mathrm{D}$ levels of $75 \mathrm{nmol} / \mathrm{L}$ or more (to define sufficient vitamin D) [8]. Strikingly, nearly all non-Hispanic blacks (97\%) and most Mexican Americans (90\%) had insufficient vitamin D levels $(<75 \mathrm{nmol} / \mathrm{L})$ [8]. The Institute of Medicine (IOM), which issued new recommended daily allowance of vitamin D and calcium in 2011, conducted a comprehensive and rigorous review of existing data on vitamin D in relation to osteoporosis and other nonskeletal outcomes - most studies conducted in non-Hispanic whitesand determined that a cutoff level of $50 \mathrm{nmol} / \mathrm{L}(20 \mathrm{ng} / \mathrm{mL})$ of serum $25(\mathrm{OH}) \mathrm{D}$ is needed to maintain bone health for most individuals $\left[9 \bullet \bullet, 10^{\bullet}\right]$. Notably, the IOM Committee concluded that the evidence that vitamin $\mathrm{D}$ or calcium protects against risk of nonskeletal chronic disease outcomes, including hypertension, type 2 diabetes, and cardiovascular disease (CVD), was inconsistent, inconclusive, and did not meet criteria for establishing cause-and-effect relationships [9••, 10•]. Optimal 25(OH)D levels for cardiovascular health remain unknown due to limited data.

\section{Cardiometabolic Risk Factors}

Vitamin D deficiency has been associated with many adverse health outcomes, including several bone diseases, certain types of cancer, multiple autoimmune diseases, and the metabolic syndrome [1-3]. Vitamin D may influence risk of CVD through multiple pathways, including inhibition of the release of proinflammatory cytokines, regulation of the renin-angiotensin system (RAS), improvement in ventricular function, favorable effects on lipid and glucose metabolism, and insulin secretion and sensitivity (Fig. 1).

For years, abdominal obesity, abnormal glucose metabolism, hypertension, and dyslipidemia (low high-density lipoprotein cholesterol and high triglycerides) have been linked as a cluster of metabolic abnormalities defined as the metabolic syndrome [11]. All components of the metabolic syndrome are associated with increased risks of major chronic diseases, including type 2 diabetes, CVD, chronic kidney disease, nonalcoholic fatty liver disease, polycystic ovary syndrome, and certain forms of cancer. The metabolic syndrome is now reaching epidemic proportion worldwide and may reflect a common underlying pathophysiology related to multiple cardiovascular and metabolic end points, collectively termed cardiometabolic disease [11]. The pathogenesis of cardiometabolic disease is a complex and multifactorial process. Cardiometabolic risk factors and their disease outcomes of hypertension, type 2 diabetes, CVD, and other comorbidities continue to be a global threat to public health.

\section{Insulin Secretion and Sensitivity}

A large body of literature has suggested that optimal vitamin D status is essential for both insulin action and secretion [3], two fundamental features in the pathogenesis of type 2 diabetes. Vitamin $\mathrm{D}$ may directly affect pancreatic $\beta$-cell function via the binding of circulating $1,25(\mathrm{OH})_{2} \mathrm{D}$ to VDR in $\beta$ cells $[2,12]$. Also, vitamin $D$ may indirectly affect calcium-dependent insulin secretion via regulation of calcium transport through the $\beta$ cells $[13,14]$. Intravenous administration of $1,25(\mathrm{OH}){ }_{2} \mathrm{D}_{3}$ was shown to increase insulin secretion and reduce blood glucose response to an intravenous glucose load in vitamin D-deficient rats [12] and rabbits [15]. The effect of vitamin D on insulin resistance may not be direct and could be mediated through its beneficial effects on adiposity. Several other mechanisms, including stimulating expression of insulin receptors, regulation of the calcium pool, and modulation of cytokine expression and activity, may also account for its beneficial effect on insulin action in peripheral tissues $[1,16]$. Human data also show that low vitamin D status is associated with impaired $\beta$-cell function, insulin resistance, and impaired glucose tolerance [3, 16-18]. Recent randomized trials appeared to support the effect of vitamin D supplementation on insulin sensitivity. In a large trial of 314 adults aged 65 years and older, taking a combined vitamin D (700 IU/ d) and calcium supplement $(500 \mathrm{mg} / \mathrm{d})$ for 3 years prevented increases in fasting plasma glucose and insulin resistance (measured by homeostasis model assessment-estimated insulin resistance [HOMA-IR]) among impaired glucosetolerant participants, but not among women with normal fasting glucose [19]. In a randomized, placebo-controlled trial of 18 healthy white males, $1,25-(\mathrm{OH})_{2} \mathrm{D}_{3}$ treatment $(1.5 \mu \mathrm{g} / \mathrm{d}$ for 7 days) did not change mean glucose, insulin, or insulin sensitivity [20]. More recently, in a randomized, double-blind, placebo-controlled trial of 92 adults at high risk of diabetes, daily vitamin D3 supplementation $(2,000 \mathrm{IU})$ with or without calcium $(800 \mathrm{mg})$ for 16 weeks 


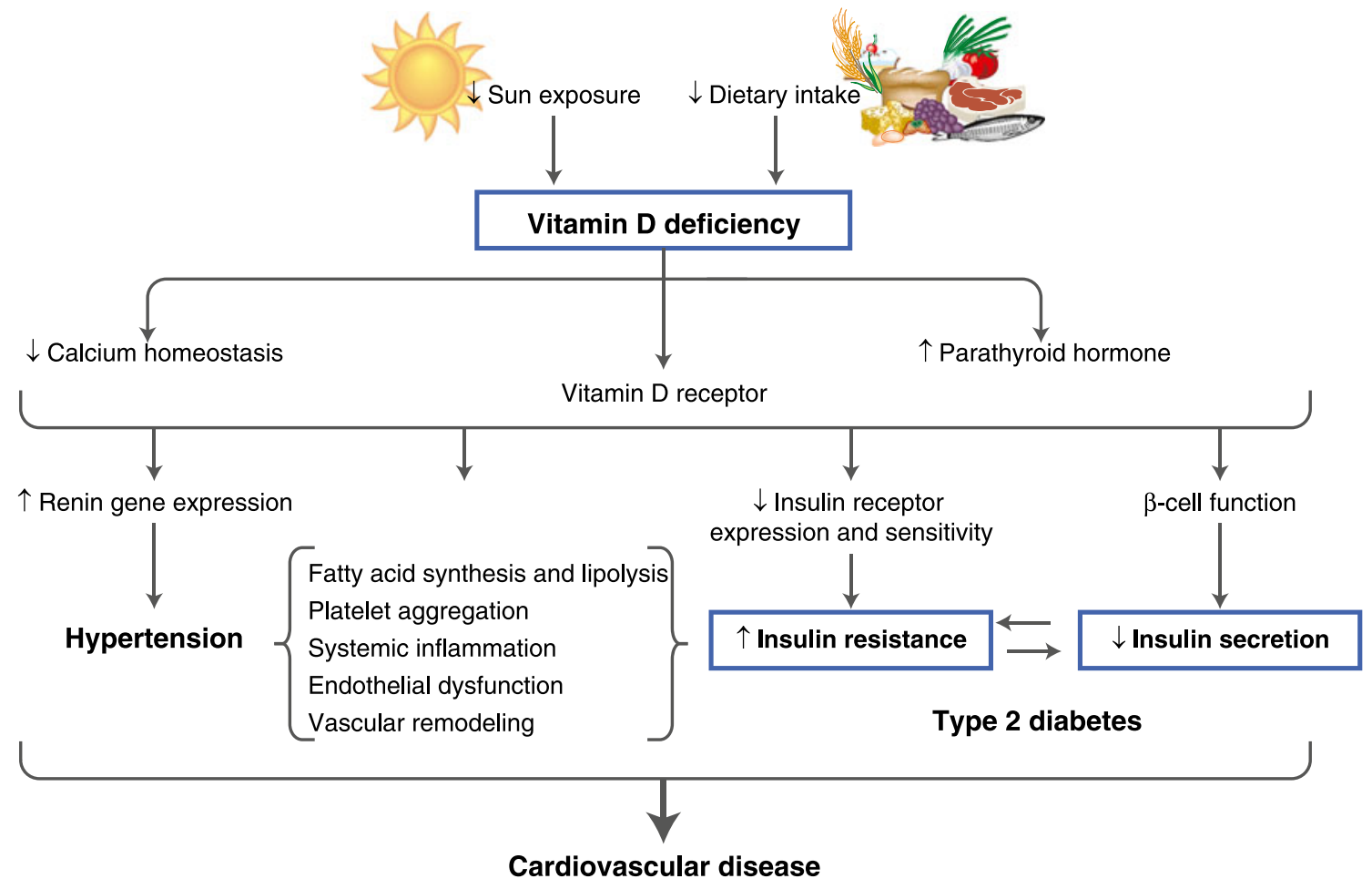

Fig. 1 Scheme showing the possible relationship between vitamin D deficiency and cardiometabolic disease

improved pancreatic $\beta$-cell function assessed by an intravenous glucose tolerance test and had a marginal effect on attenuating the rise in glycosylated hemoglobin $(\mathrm{HbAlc})$ [21]. Given limited sample sizes and short duration, these clinical trials did not have adequate power. Furthermore, differences in study population, duration of diabetes, glycemic treatment, and intervention periods, coupled with the fact that different vitamin D doses and forms were used may explain the inconsistent results from these trials. The true beneficial effect of vitamin $D$ in improving insulin sensitivity and pancreatic $\beta$-cell function in nondiabetic individuals has yet to be conclusively demonstrated without definitive evidence from long-term and well-designed controlled trials.

\section{Adiposity}

The interrelationship between vitamin D status and adiposity is complex and may be reciprocal. Some [17, 22-24], but not all [25-27] observational studies have shown an inverse association between 25(OH)D levels and adiposity. Although the underlying mechanisms are not wellunderstood, increased storage of $25(\mathrm{OH}) \mathrm{D}$ in adipose tissue in obese individuals is a plausible explanation [23]. Also, less sun exposure due to limited mobility and/or more subcutaneous fat deposits in obese individuals may lead to reduced vitamin D synthesis in the skin $[28,29]$. On the other hand, vitamin D may directly affect adiposity. Vitamin
D is an important determinant of circulating parathyroid hormone (PTH) levels. PTH stimulates calcium influx into adipocytes, which enhances lipogenesis and inhibits lipolysis, leading to accumulation of fat [30]. Of note, measurement error due to self-reporting of anthropometric variables, including weight, height, and waist and hip circumferences, could have affected the results in previous cohort studies based on self-reported data. Future mechanistic and large cohort studies with longitudinal data are needed to help us understand the interrelations between vitamin $\mathrm{D}$ and adiposity.

\section{Systemic Inflammation}

Vitamin D has anti-inflammatory and immunomodulatory effects $\left[31 \bullet \bullet\right.$. Experimental data suggest that $1,25(\mathrm{OH})_{2} \mathrm{D}$ inhibits proinflammatory cytokines such as interleukin (IL)6 and tumor necrosis factor- $\alpha$, decreases $C$-reactive protein, upregulates production of the anti-inflammatory cytokine IL-10 [32], and regulates expression of matrix metalloproteinase-9 [33]. VDRs are found on dendritic cells, $\mathrm{T}$ and $\mathrm{B}$ lymphocytes, and macrophages. Vitamin $\mathrm{D}$ has complex effects in both adaptive and innate immunity. The net effect of vitamin D in T cells is to suppress T-helper type 1 (Th1)-driven inflammatory responses while promoting a Th2 regulatory phenotype. Vitamin D promotes monocyte differentiation into macrophages and enhances their chemotactic and phagocytotic capacity as well as their bacterial 
killing [31••]. On the other hand, vitamin D prevents monocytes from releasing inflammatory cytokines and chemokines and reduces their antigen-presenting and T-cellstimulatory capacities, which may attenuate the degree of the innate inflammatory response $[31 \bullet \cdot]$. Despite the in vitro and animal evidence, whether vitamin D supplementation reduces inflammation in those without overt autoimmunity is unclear, particularly among healthy ambulatory individuals. Furthermore, vitamin D insufficiency has been associated with autoimmune diseases such as type 1 diabetes, multiple sclerosis, rheumatoid arthritis, inflammatory bowel disease, and psoriasis [34••]. However, consistent epidemiologic or experimental evidence of an effect of vitamin D on autoimmune disease in humans is lacking, as recently reviewed comprehensively by Kriegel et al. [34••].

\section{Cardiometabolic Diseases}

\section{Hypertension}

Vitamin D has potential antihypertensive effects, mainly through its effects on the RAS [35•]. Human study of the association between vitamin D and the RAS has been scant. Some cross-sectional analyses in the NHANES representative sample of the US population have reported that circulating 25 $(\mathrm{OH}) \mathrm{D}$ and PTH were independently associated with BP and with the presence of hypertension or prehypertension, though directionality remains to be elucidated in prospective studies [36]. Most cross-sectional studies that failed to observe a significant relationship between $25(\mathrm{OH}) \mathrm{D}$ levels and BP or hypertension had small sample sizes and therefore limited statistical power.[37] Two large cross-sectional studies, the Amsterdam Longitudinal Aging Study and the RanchoBernardo Study, did not find an association $[38,39]$. Their null findings may be attributed to a high prevalence of participants with prevalent hypertension and use of antihypertensive medication (80\%) [39] or with normal 25(OH)D levels (>30 ng/ $\mathrm{mL})(98 \%)$ [38]. Several prospective studies have examined the association between baseline $25(\mathrm{OH}) \mathrm{D}$ levels and incident hypertension or longitudinal change in BP [40-42] but yielded mixed results. In a prospective cohort study including 613 men and 1,198 women who did not have hypertension at baseline, those with $25(\mathrm{OH}) \mathrm{D}$ levels less than $15 \mathrm{ng} / \mathrm{mL}$, compared with $30 \mathrm{ng} / \mathrm{mL}$ or greater, had a relative risk (RR) of incident hypertension of 2.67 (95\% CI, 1.05-6.79) after adjusting for multiple demographic and lifestyle factors [41]. In a nested case-control study $(n=1,500)$ within the prospective Nurses' Health Study II cohort [40], after multivariable adjustment (including PTH), baseline 25(OH)D levels were associated with hypertension with an OR of 1.66 (95\% CI, 1.11-2.48) comparing the lowest to highest quartile. A population-based study among women 22 to 44 years of age found that low levels of $25(\mathrm{OH}) \mathrm{D}$ were associated with incident systolic hypertension (RR, 3.0 [95 \% CI, 1.1-8.7]). However, recent findings from three longitudinal studies showed that $25(\mathrm{OH}) \mathrm{D}$ levels were not associated with the change in BP over time [42-44]. In these studies, changes in $25(\mathrm{OH}) \mathrm{D}$ over time, use of antihypertensive medications, measurement errors, or confounders may account for the null results.

In contrast, the results from interventional studies that have analyzed the effect of vitamin D supplementation on BP are mixed, with the majority of these analyses being small-scale trials not specifically designed to examine change in BP. A total of 13 randomized trials of vitamin D supplementation have reported results of change in BP comparing active supplementation with placebo [35•]. Many sources of heterogeneity may have contributed to the inconsistency in previous clinical trials, including small sample size; incomplete randomization; the lack of blinding in design; variable durations of follow-up; high rates of noncompliance; and differences in vitamin $\mathrm{D}$ treatment protocols, vitamin $\mathrm{D}$ formulation and dose, and study populations. In addition, BP assessment remains an important issue because $\mathrm{BP}$ is subject to a substantial degree of measurement error and can vary considerably in an individual from time to time. Most trials used clinic measurement and few trials used the 24-hour ambulatory BP. Secondary analysis of the largest randomized trial of calcium and vitamin D, the Women's Health Initiative (WHI) clinical trial, did not observe any effect from daily intake of $1,000 \mathrm{mg}$ of elemental calcium plus 400 IU of vitamin D3 on BP and incident hypertension over 7 years of follow-up [45•]. However, the dose of vitamin D used in the WHI (400 IU/d) has been considered too low to raise serum $25(\mathrm{OH}) \mathrm{D}$ levels to the optimal levels for skeletal and nonskeletal health, particularly because the great majority of women in the WHI have been found to have baseline 25(OH)D less than $30 \mathrm{ng} / \mathrm{mL}$ [45•]. Additional research is needed to assess whether vitamin $\mathrm{D}$ with optimal dosage is beneficial for primary prevention of hypertension in the general population.

\section{Type 2 Diabetes}

To date, accumulating evidence in animal and laboratory studies indicates that vitamin D is essential for insulin secretion and action. Many clinical and epidemiologic studies have investigated the association of serum and dietary vitamin D with type 2 diabetes in humans. Earlier ecological studies have reported high prevalences of glucose intolerance and type 2 diabetes associated with vitamin $\mathrm{D}$ deficiency in some ethnic populations [46, 47]. Most relevant observational studies using dietary assessment information have focused on vitamin D-rich food groups such as dairy products and fish rather than specifically examining supplemental or total intake of vitamin D [48, 49]. It should be noted that dietary vitamin D intake is likely limited by measurement error and also does not 
address the major non-dietary component of vitamin D levels from sun exposure. Moreover, the observed associations of dietary vitamin D intake with improved glucose metabolism and decreased risk of incident diabetes may be the result of confounding or of other components of foods that are highly correlated with vitamin D and calcium. The inconsistent results may also reflect that dietary vitamin $\mathrm{D}$ is not the major source of vitamin D in the human body.

Epidemiologic evidence relating lower vitamin D status, as assessed by circulating 25(OH)D levels, to hyperglycemia, insulin resistance, or higher prevalence of type 2 diabetes is primarily derived from cross-sectional reports [3]. Only recently have prospective observational studies accumulated to show a relationship between low circulating levels of $25(\mathrm{OH})$ $\mathrm{D}$ and higher incidence of type 2 diabetes. A recent pooled analysis of two nested case-control studies of 412 incident cases of type 2 diabetes and 986 controls with 22 years of follow-up found a strong inverse association between serum $25(\mathrm{OH}) \mathrm{D}$ and type 2 diabetes risk in men, but not in women, after adjustment for confounding factors (the highest [mean, $69 \mathrm{nmol} / \mathrm{L}$ ] vs lowest quartile [mean, $22 \mathrm{nmol} / \mathrm{L}$ ]; OR, 0.28 [ $95 \%$ CI, 0.10-0.81] in men and 1.14 [95\% CI, 0.60-2.17] in women) [50]. Such sex difference was not observed in subsequent prospective studies. It may be due to residual confounding and statistical fluctuation because of small sample size. Overall, prospective data on serum $25(\mathrm{OH}) \mathrm{D}$ and type 2 diabetes have been suggestive but inconclusive.

The largest randomized trial of vitamin D supplementation, the WHI clinical trial, evaluated vitamin D supplementation for the primary prevention of clinical diabetes in 33,951 initially nondiabetic postmenopausal women [51]. However, $400 \mathrm{IU} / \mathrm{d}$ of vitamin D raised median levels of serum $25(\mathrm{OH})$ D from 42.3 to only $54.1 \mathrm{nmol} / \mathrm{L}(\sim 12 \mathrm{nmol} / \mathrm{L})$, which is below the optimal value of $90 \mathrm{nmol} / \mathrm{L}$ or more for skeletal and nonskeletal health [52]. Clearly, direct evidence from future large-scale clinical trials of higher-dose vitamin D supplementation is warranted to clarify any beneficial effects of vitamin D supplementation on primary prevention of type 2 diabetes. Although randomized trials are critical for establishing cause-and-effect relationships between vitamin D and health outcomes, they will not be able to address all the unanswered questions based on their fixed dose (or at most a few doses) of vitamin $\mathrm{D}$ and narrow ranges of $25(\mathrm{OH}) \mathrm{D}$ levels in the study population. Prospective data have the ability to assess $25(\mathrm{OH}) \mathrm{D}$ thresholds and further our understanding of the physiology of vitamin $\mathrm{D}$ in relation to diabetes risk in the full spectrum of $25(\mathrm{OH}) \mathrm{D}$ levels.

\section{Cardiovascular Disease}

Effects of vitamin D on cardiometabolic risk factors, as reviewed above, would potentially lead to a change in the risk of CVD events. Several lines of epidemiologic evidence suggest a cardio- and cerebroprotective role for vitamin D. First, ecological studies show higher CVD mortality during the winter and in regions with less average exposure to UVB radiation from the sun [53]. Second, though not entirely consistent, results of cross-sectional, case-control, and cohort studies in healthy and ill populations suggest favorable associations in relation to vitamin $\mathrm{D}$ - as measured by circulating $25(\mathrm{OH}) \mathrm{D}$, sun exposure, or dietary or supplement intake - on vascular risk factors, particularly hypertension [41, 54]; impaired glucose tolerance, decreased insulin sensitivity, or type 2 diabetes [3, 55]; and inflammation [33]. Low levels of circulating $25(\mathrm{OH}) \mathrm{D}$ have been found in patients with vascular calcification [56], greater carotid intima-media thickness [57], myocardial infarction [58], stroke [59], and other forms of vascular disease [60]. Third, prospective studies of healthy populations show that low bone density, often a result of vitamin D insufficiency, predicts increased risk of CVD [61, 62]. Prospective epidemiologic data on the association between vitamin $\mathrm{D}$ and clinical cardiovascular events are limited. Recent analyses from the Framingham Offspring Study suggest a significant relationship between low serum 25(OH)D and high risk of incident CVD ( $<37.5$ vs $\geq 37.5 \mathrm{nmol} / \mathrm{L}$; RR, $1.62[95 \% \mathrm{CI}$, 1.11-2.36]) [63]. In the Health Professionals Follow-Up Study, there was also a significant association between low serum $25(\mathrm{OH}) \mathrm{D}$ and high incident coronary heart disease risk ( $\leq 37.5 \mathrm{vs} \geq 75 \mathrm{nmol} / \mathrm{L}$; RR, 2.09 [95\% CI, 1.24-3.54]) [64]. Overall, some, but not all, prospective studies found that lower 25(OH)D levels were associated with increased risk of incident CVD, including fatal cardiovascular events (cardiac or stroke), nonfatal stroke, and nonfatal myocardial infarction [65]. Some studies suggest a U-shaped relationship, with increased risk of CVD at both high and low 25 $(\mathrm{OH}) \mathrm{D}$ levels. Obviously, the existing evidence is limited by the quality of the published studies. There was also substantial heterogeneity among studies, especially in vitamin D thresholds used, ethnic groups, outcomes specified, and confounders adjusted for. Moreover, most studies included only white participants, which limited the generalizability of the study findings to other racial groups. There are considerable variations in the rate of cardiovascular events and mortality between American non-Hispanic white and African American/black groups. The reasons for this disparity may relate to differential risk factor profiles of these two ethnic groups. Further research is needed to clarify whether differences in 25(OH)D and PTH levels by ethnicity might, at least in part, explain ethnic differences in CVD.

Indeed, the potential effects of vitamin D on CVD are supported by evidence showing an association between supplemental vitamin D use and CVD. We previously conducted a systematic review of studies published in English up to July 2009 involving 17 prospective studies and randomized trials that examined vitamin D supplementation 
and subsequent cardiovascular events [66•]. We found that five prospective studies of patients receiving dialysis and one study in a general population showed consistent reductions in CVD mortality among adults who received vitamin D supplements. Secondary analyses in eight randomized trials showed a slight but statistically nonsignificant reduction in CVD risk (pooled RR, 0.90 [95 \% CI, 0.77-1.05]) with vitamin $\mathrm{D}$ supplementation at moderate to high doses $(\sim 1,000 \mathrm{IU} / \mathrm{d})$, but not with calcium supplementation (RR, 1.14 [95\% CI, 0.92-1.41]) or a combination of vitamin D and calcium supplementation (RR, 1.04 [9nCI, 0.92-1.18]) compared with placebo [66•]. The small number of studies, the lack of trials designed specifically to assess effects on cardiovascular outcomes, and large between-study heterogeneity preclude definitive conclusions. In the WHI $\mathrm{CaD}$ trial, the intervention of calcium $(1,000 \mathrm{mg} / \mathrm{d})$ plus low-dose vitamin D3 (400 IU/d) for 7 years did not reduce coronary heart disease or stroke incidence in 36,282 postmenopausal women [67]. Overall, these findings indicate that a protective effect of vitamin D supplementation on CVD is possible but that a large trial of vitamin $\mathrm{D}$ with an adequate dose is needed to assess its specific role in CVD prevention. Further randomized trials clearly will be important in establishing causality of the vitamin D-CVD relationship.

\section{Ongoing Vitamin D Intervention Trial}

Accumulating evidence from the new IOM guidelines suggests that vitamin $\mathrm{D}$ intake well above currently recommended amounts of $600 \mathrm{IU} / \mathrm{d}$ for adults aged 50 to 70 and $800 \mathrm{IU} / \mathrm{d}$ for adults older than 70 years of age is necessary for health benefits. Among postmenopausal women in the WHI, $400 \mathrm{IU} / \mathrm{d}$ of vitamin D3 raised median plasma $25(\mathrm{OH})$ D from 42.3 to only $54.1 \mathrm{nmol} / \mathrm{L}$ [51, 68]. In a review of studies of serum $25(\mathrm{OH}) \mathrm{D}$ in relation to multiple end points, including bone mineral density; lower extremity function; dental health; and risk of falls, fractures, and colorectal cancer, Bischoff-Ferrari et al. [69] found that for most end points, advantageous $25(\mathrm{OH}) \mathrm{D}$ levels began at $75 \mathrm{nmol} / \mathrm{L}$, and optimal levels were 90 to $100 \mathrm{nmol} / \mathrm{L}$. An average older adult requires an oral vitamin D3 intake of at least 800 to $1,000 \mathrm{IU} / \mathrm{d}(20-25 \mu \mathrm{g})$ to achieve a serum $25(\mathrm{OH}) \mathrm{D}$ of $75 \mathrm{nmol} / \mathrm{L}$ [52]. Extrapolation of these data suggests that it would require a dose of 2,000 IU/d $(50 \mu \mathrm{g} / \mathrm{d})$ to achieve a mean 25(OH)D level of about 80 to $90 \mathrm{nmol} / \mathrm{L}$. The ongoing VITamin D and Omeg $A-3$ Tria $L$ (VITAL) is a large, randomized, double-blind, placebo-controlled, two-by-two factorial trial of vitamin D (in the form of vitamin D3 [cholecalciferol], 2,000 IU/d) and marine omega-3 fatty acid (eicosapentaenoic acid+docosahexaenoic acid, $1 \mathrm{~g} / \mathrm{d}$ ) supplements in the primary prevention of cancer and CVD in a multiethnic population of 20,000 US men 50 years of age and older and women 55 years of age and older [70••]. The vitamin D dose tested in the VITAL trial, 2,000 IU $(50 \mu \mathrm{g}) /$ $\mathrm{d}$, is well below the no-observed-adverse-effect level of 4,000 IU specified by the European Commission Scientific Committee on Food [71]. The mean treatment period of the VITAL trial will be 5 years. Yearly follow-up questionnaires will assess treatment compliance (plasma biomarker measures will also assess compliance in a random sample of participants), use of non-study drugs or supplements, occurrence of end points, and cancer and vascular risk factors. The primary aims of the trial are to test whether vitamin D3 or marine omega-3 fatty acid supplementation reduces the risk of total cancer and major CVD events (a composite end point of myocardial infarction, stroke, and cardiovascular mortality) $[70 \bullet \bullet]$. Ancillary studies will investigate whether these agents affect the risk of diabetes and glucose intolerance, hypertension, cognitive decline, depression, osteoporosis and fracture, physical disability and falls, asthma and other respiratory diseases, infections, and autoimmune disorders $[70 \bullet \bullet$. The widespread attention for potential health benefits of vitamin $\mathrm{D}$ and increasing use of individual vitamin D supplements in the general population underscore the need for timely initiation of a large, randomized trial such as VITAL to test the long-term benefits and risks of vitamin D supplementation rigorously. The results of VITAL are expected to inform individual decisions, clinical recommendations, and public health guidelines regarding the use of vitamin D supplements for the primary prevention of cancer and CVD.

\section{Conclusions}

The link between vitamin D status and cardiometabolic disease is of great interest and potentially important for public health. There is growing evidence from experimental studies to indicate that vitamin D may influence risk of cardiometabolic disease through multiple pathways, including insulin secretion and action, adiposity, inflammation, lipids, RAS, and BP. However, the majority of studies on the association of vitamin D with cardiometabolic disease in humans have been observational in nature, hindering the ability to make further recommendations on vitamin D supplementation. Future well-designed randomized clinical trials are warranted to clarify the potential beneficial effect of vitamin D supplementation on preventing cardiometabolic disease, including hypertension, type 2 diabetes, and CVD.

Acknowledgments Dr. Song is the principal investigator of an ancillary study (National Institutes of Health [NIH] R01-DK088078) investigating diabetes prevention in VITAL. VITAL is a large-scale, randomized trial of vitamin $\mathrm{D}$ and omega-3 fatty acids for the prevention of cancer and CVD and is funded by the NIH (Bethesda, MD). 
Dr. Wang was supported by a career development grant HL095649 from the NIH. The NIH had no role in the study design and conduct or the decision to write this review.

Disclosure No potential conflicts of interest relevant to this article were reported.

\section{References}

Papers of particular interest, published recently, have been highlighted as:

- Of importance

-. Of importance

1. Holick MF. Vitamin D deficiency. N Engl J Med. 2007;357 (3):266-81.

2. Norman AW, Frankel JB, Heldt AM, Grodsky GM. Vitamin D deficiency inhibits pancreatic secretion of insulin. Science. 1980;209(4458):823-5.

3. Pittas AG, Lau J, Hu FB, Dawson-Hughes B. The role of vitamin $\mathrm{D}$ and calcium in type 2 diabetes. A systematic review and metaanalysis. J Clin Endocrinol Metab. 2007;92(6):2017-29.

4. Clemens TL, Adams JS, Henderson SL, Holick MF. Increased skin pigment reduces the capacity of skin to synthesise vitamin D3. Lancet. 1982;1(8263):74-6.

5. Nesby-O'Dell S, Scanlon KS, Cogswell ME, Gillespie C, Hollis BW, Looker AC, Allen C, Doughertly C, Gunter EW, Bowman BA. Hypovitaminosis D prevalence and determinants among African American and white women of reproductive age: third National Health and Nutrition Examination Survey, 1988-1994. Am J Clin Nutr. 2002;76(1):187-92.

6. Scragg R, Sowers M, Bell C. Serum 25-hydroxyvitamin D, diabetes, and ethnicity in the Third National Health and Nutrition Examination Survey. Diabetes Care. 2004;27(12):2813-8.

7. MacLaughlin J, Holick MF. Aging decreases the capacity of human skin to produce vitamin D3. J Clin Invest. 1985;76(4):1536-8.

8. Ginde AA, Liu MC, Camargo Jr CA. Demographic differences and trends of vitamin D insufficiency in the US population, 19882004. Arch Intern Med. 2009;169(6):626-32.

9. •- The Institute of Medicine (IOM). Dietary Reference Intakes for Calcium and Vitamin D. Washington: The National Academies Press; 2011. This IOM report proposed new reference values for calcium and vitamin D based on a comprehensive review of the evidence for both skeletal and extraskeletal outcomes and concluded that the evidence supports a role for vitamin $D$ and calcium in bone health, but not in other health conditions.

10. - Ross AC, Manson JE, Abrams SA, Aloia JF, Brannon PM, Clinton SK, Durazo-Arvizu RA, Gallagher JC, Gallo RL, Jones G, Kovacs CS, et al. The 2011 report on dietary reference intakes for calcium and vitamin D from the Institute of Medicine: what clinicians need to know. J Clin Endocrinol Metab. 2011;96(1):538. This article summarizes the 2011 IOM report on dietary requirements for calcium and vitamin $D$ and calls for additional research, including large-scale, randomized clinical trials.

11. Eckel RH, Grundy SM, Zimmet PZ. The metabolic syndrome. Lancet. 2005;365(9468):1415-28.

12. Cade C, Norman AW. Vitamin D3 improves impaired glucose tolerance and insulin secretion in the vitamin D-deficient rat in vivo. Endocrinology. 1986;119(1):84-90.

13. Beaulieu C, Kestekian R, Havrankova J, Gascon-Barre M. Calcium is essential in normalizing intolerance to glucose that accompanies vitamin D depletion in vivo. Diabetes. 1993;42(1):35-43.
14. Milner RD, Hales CN. The role of calcium and magnesium in insulin secretion from rabbit pancreas studied in vitro. Diabetologia. 1967;3 (1):47-9.

15. Nyomba BL, Bouillon R, De Moor P. Influence of vitamin D status on insulin secretion and glucose tolerance in the rabbit. Endocrinology. 1984;115(1):191-7.

16. Norman AW. From vitamin D to hormone D: fundamentals of the vitamin D endocrine system essential for good health. Am J Clin Nutr. 2008;88(2):491S-9S.

17. Chiu KC, Chu A, Go VL, Saad MF. Hypovitaminosis D is associated with insulin resistance and beta cell dysfunction. Am J Clin Nutr. 2004;79(5):820-5.

18. Holick MF. Vitamin D: importance in the prevention of cancers, type 1 diabetes, heart disease, and osteoporosis. Am J Clin Nutr. 2004;79(3):362-71.

19. Pittas AG, Harris SS, Stark PC, Dawson-Hughes B. The effects of calcium and vitamin D supplementation on blood glucose and markers of inflammation in nondiabetic adults. Diabetes Care. 2007;30(4):980-6.

20. Fliser D, Stefanski A, Franek E, Fode P, Gudarzi A, Ritz E. No effect of calcitriol on insulin-mediated glucose uptake in healthy subjects. Eur J Clin Invest. 1997;27(7):629-33.

21. Mitri J, Dawson-Hughes B, Hu FB, Pittas AG. Effects of vitamin $\mathrm{D}$ and calcium supplementation on pancreatic beta cell function, insulin sensitivity, and glycemia in adults at high risk of diabetes: the Calcium and Vitamin D for Diabetes Mellitus (CaDDM) randomized controlled trial. Am J Clin Nutr. 2011;94(2):486-94.

22. Bell NH, Epstein S, Greene A, Shary J, Oexmann MJ, Shaw S. Evidence for alteration of the vitamin D-endocrine system in obese subjects. J Clin Invest. 1985;76(1):370-3.

23. Wortsman J, Matsuoka LY, Chen TC, Lu Z, Holick MF. Decreased bioavailability of vitamin D in obesity. Am J Clin Nutr. 2000;72 (3):690-3.

24. Snijder MB, van Dam RM, Visser M, Deeg DJ, Dekker JM, Bouter LM, Seidell JC, Lips P. Adiposity in relation to vitamin D status and parathyroid hormone levels: a population-based study in older men and women. J Clin Endocrinol Metab. 2005;90(7):4119-23.

25. Arunabh S, Pollack S, Yeh J, Aloia JF. Body fat content and 25hydroxyvitamin D levels in healthy women. J Clin Endocrinol Metab. 2003;88(1):157-61.

26. Need AG, Morris HA, Horowitz M, Nordin C. Effects of skin thickness, age, body fat, and sunlight on serum 25-hydroxyvitamin D. Am J Clin Nutr. 1993;58(6):882-5.

27. Scragg R, Holdaway I, Singh V, Metcalf P, Baker J, Dryson E. Serum 25-hydroxyvitamin D3 is related to physical activity and ethnicity but not obesity in a multicultural workforce. Aust N Z J Med. 1995;25(3):218-23.

28. Bell NH, Greene A, Epstein S, Oexmann MJ, Shaw S, Shary J. Evidence for alteration of the vitamin D-endocrine system in blacks. J Clin Invest. 1985;76(2):470-3.

29. Parikh SJ, Edelman M, Uwaifo GI, Freedman RJ, Semega-Janneh M, Reynolds J, Yanovski JA. The relationship between obesity and serum 1,25-dihydroxy vitamin D concentrations in healthy adults. J Clin Endocrinol Metab. 2004;89(3):1196-9.

30. Zemel MB. Regulation of adiposity and obesity risk by dietary calcium: mechanisms and implications. J Am Coll Nutr. 2002;21 (2): $146 \mathrm{~S}-51 \mathrm{~S}$.

31. - Hewison M: Vitamin D and immune function: an overview. Proc Nutr Soc. 2011;1-12. This review summarizes experimental and observational evidence linking vitamin $D$ to innate and adaptive immunity.

32. Canning MO, Grotenhuis K, de Wit H, Ruwhof C, Drexhage HA. 1-alpha,25-Dihydroxyvitamin $\mathrm{D} 3(1,25(\mathrm{OH})(2) \mathrm{D}(3))$ hampers the maturation of fully active immature dendritic cells from monocytes. Eur J Endocrinol. 2001;145(3):351-7.

33. Timms PM, Mannan N, Hitman GA, Noonan K, Mills PG, Syndercombe-Court D, Aganna E, Price CP, Boucher BJ. 
Circulating MMP9, vitamin D and variation in the TIMP-1 response with VDR genotype: mechanisms for inflammatory damage in chronic disorders? QJM. 2002;95(12):787-96.

34. • Kriegel MA, Manson JE, Costenbader KH: Does vitamin D affect risk of developing autoimmune disease?: a systematic review. Semin Arthritis Rheum 2011, 40(6):512-531 e518. The systematic review evaluates the epidemiologic evidence linking vitamin $D$ level or intake to autoimmune disease risk.

35. - Vaidya A, Forman JP. Vitamin D and hypertension: current evidence and future directions. Hypertension. 2010;56(5):774-9. This commentary reviews the physiology and function of vitamin $D$ with regard to $B P$ and examines the current observational and intervention data in hypertension.

36. Zhao G, Ford ES, Li C, Kris-Etherton PM, Etherton TD, Balluz LS. Independent associations of serum concentrations of 25hydroxyvitamin D and parathyroid hormone with blood pressure among US adults. J Hypertens. 2010;28(9):1821-8.

37. Scragg R, Holdaway I, Jackson R, Lim T. Plasma 25-hydroxyvitamin D3 and its relation to physical activity and other heart disease risk factors in the general population. Ann Epidemiol. 1992;2(5):697-703.

38. Reis JP, von Muhlen D, Kritz-Silverstein D, Wingard DL, BarrettConnor E. Vitamin D, parathyroid hormone levels, and the prevalence of metabolic syndrome in community-dwelling older adults. Diabetes Care. 2007;30(6):1549-55.

39. Snijder MB, Lips P, Seidell JC, Visser M, Deeg DJ, Dekker JM, van Dam RM. Vitamin D status and parathyroid hormone levels in relation to blood pressure: a population-based study in older men and women. J Intern Med. 2007;261(6):558-65.

40. Forman JP, Curhan GC, Taylor EN. Plasma 25-hydroxyvitamin D levels and risk of incident hypertension among young women. Hypertension. 2008;52(5):828-32.

41. Forman JP, Giovannucci E, Holmes MD, Bischoff-Ferrari HA, Tworoger SS, Willett WC, Curhan GC. Plasma 25hydroxyvitamin D levels and risk of incident hypertension. Hypertension. 2007;49(5):1063-9.

42. Forouhi NG, Luan J, Cooper A, Boucher BJ, Wareham NJ. Baseline serum 25-hydroxy vitamin $d$ is predictive of future glycemic status and insulin resistance: the Medical Research Council Ely Prospective Study 1990-2000. Diabetes. 2008;57(10):2619-25.

43. Jorde R, Figenschau Y, Emaus N, Hutchinson M, Grimnes G. Serum 25-hydroxyvitamin D levels are strongly related to systolic blood pressure but do not predict future hypertension. Hypertension. 2010;55(3):792-8.

44. Margolis KL, Martin LW, Ray RM, Kerby TJ, Allison MA, Curb JD, Kotchen TA, Liu S, Wassertheil-Smoller S, Manson JE. A prospective study of serum 25-hydroxyvitamin D levels, blood pressure, and incident hypertension in postmenopausal women. Am J Epidemiol. 2012;175(1):22-32.

45. - Margolis KL, Ray RM, Van Horn L, Manson JE, Allison MA, Black HR, Beresford SA, Connelly SA, Curb JD, Grimm Jr RH, Kotchen TA, et al. Effect of calcium and vitamin D supplementation on blood pressure: the Women's Health Initiative Randomized Trial. Hypertension. 2008;52(5):847-55. This is the first large randomized, placebo-controlled trial of vitamin D plus calcium supplementation in relation to BP change and incidence of hypertension.

46. Boucher BJ, Mannan N, Noonan K, Hales CN, Evans SJ. Glucose intolerance and impairment of insulin secretion in relation to vitamin D deficiency in east London Asians. Diabetologia. 1995;38(10):1239-45.

47. Gedik O, Akalin S. Effects of vitamin D deficiency and repletion on insulin and glucagon secretion in man. Diabetologia. 1986;29(3):142-5.

48. Liu S, Song Y, Ford ES, Manson JE, Buring JE, Ridker PM. Dietary calcium, vitamin $\mathrm{D}$, and the prevalence of metabolic syndrome in middle-aged and older U.S. women. Diabetes Care. 2005;28(12):2926-32.
49. Pittas AG, Dawson-Hughes B, Li T, Van Dam RM, Willett WC, Manson JE, Hu FB. Vitamin D and calcium intake in relation to type 2 diabetes in women. Diabetes Care. 2006;29(3):650-6.

50. Knekt P, Laaksonen M, Mattila C, Harkanen T, Marniemi J, Heliovaara M, Rissanen H, Montonen J, Reunanen A. Serum vitamin D and subsequent occurrence of type 2 diabetes. Epidemiology. 2008;19 (5):666-71.

51. de Boer IH, Tinker LF, Connelly S, Curb JD, Howard BV, Kestenbaum B, Larson JC, Manson JE, Margolis KL, Siscovick DS, Weiss NS. Calcium plus vitamin D supplementation and the risk of incident diabetes in the Women's Health Initiative. Diabetes Care. 2008;31 (4):701-7.

52. Dawson-Hughes B, Heaney RP, Holick MF, Lips P, Meunier PJ, Vieth R. Estimates of optimal vitamin D status. Osteoporos Int. 2005;16(7):713-6.

53. Zittermann A, Schleithoff SS, Koerfer R. Putting cardiovascular disease and vitamin D insufficiency into perspective. Br J Nutr. 2005;94(4):483-92.

54. Wang L, Manson JE, Buring JE, Lee IM, Sesso HD. Dietary intake of dairy products, calcium, and vitamin D and the risk of hypertension in middle-aged and older women. Hypertension. 2008;51 (4):1073-9.

55. Mattila C, Knekt P, Mannisto S, Rissanen H, Laaksonen MA, Montonen J, Reunanen A. Serum 25-hydroxyvitamin D concentration and subsequent risk of type 2 diabetes. Diabetes Care. 2007;30(10):2569-70.

56. Watson KE, Abrolat ML, Malone LL, Hoeg JM, Doherty T, Detrano $\mathrm{R}$, Demer LL. Active serum vitamin D levels are inversely correlated with coronary calcification. Circulation. 1997;96(6):1755-60.

57. Targher G, Bertolini L, Padovani R, Zenari L, Scala L, Cigolini M, Arcaro G. Serum 25-hydroxyvitamin D3 concentrations and carotid artery intima-media thickness among type 2 diabetic patients. Clin Endocrinol (Oxf). 2006;65(5):593-7.

58. Scragg R, Jackson R, Holdaway IM, Lim T, Beaglehole R. Myocardial infarction is inversely associated with plasma $25-$ hydroxyvitamin D3 levels: a community-based study. Int J Epidemiol. 1990;19(3):559-63.

59. Poole KE, Loveridge N, Barker PJ, Halsall DJ, Rose C, Reeve J, Warburton EA. Reduced vitamin D in acute stroke. Stroke. 2006;37(1):243-5.

60. Melamed ML, Muntner P, Michos ED, Uribarri J, Weber C, Sharma J, Raggi P. Serum 25-hydroxyvitamin D levels and the prevalence of peripheral arterial disease: results from NHANES 2001 to 2004. Arterioscler Thromb Vasc Biol. 2008;28(6):1179-85.

61. von der Recke P, Hansen MA, Hassager C. The association between low bone mass at the menopause and cardiovascular mortality. Am J Med. 1999;106(3):273-8.

62. Samelson EJ, Kiel DP, Broe KE, Zhang Y, Cupples LA, Hannan MT, Wilson PW, Levy D, Williams SA, Vaccarino V. Metacarpal cortical area and risk of coronary heart disease: the Framingham Study. Am J Epidemiol. 2004;159(6):589-95.

63. Wang TJ, Pencina MJ, Booth SL, Jacques PF, Ingelsson E, Lanier K, Benjamin EJ, D'Agostino RB, Wolf M, Vasan RS. Vitamin D deficiency and risk of cardiovascular disease. Circulation. 2008;117(4):503-11.

64. Giovannucci E, Liu Y, Hollis BW, Rimm EB. 25-hydroxyvitamin $\mathrm{D}$ and risk of myocardial infarction in men: a prospective study. Arch Intern Med. 2008;168(11):1174-80.

65. Pittas AG, Chung M, Trikalinos T, Mitri J, Brendel M, Patel K, Lichtenstein AH, Lau J, Balk EM. Systematic review: vitamin D and cardiometabolic outcomes. Ann Intern Med. 2010;152 (5):307-14.

66. - Wang L, Manson JE, Song Y, Sesso HD. Systematic review: vitamin D and calcium supplementation in prevention of cardiovascular events. Ann Intern Med. 2010;152(5):315-23. This systematic review summarizes the effects of calcium and vitamin $D$ 
supplements on vascular events and suggests that moderate to high doses of vitamin D supplements may reduce CVD risk, but calcium supplements may not.

67. Hsia J, Heiss G, Ren H, Allison M, Dolan NC, Greenland P, Heckbert SR, Johnson KC, Manson JE, Sidney S, Trevisan M. Calcium/vitamin D supplementation and cardiovascular events. Circulation. 2007;115(7):846-54.

68. Wactawski-Wende J, Kotchen JM, Anderson GL, Assaf AR, Brunner RL, O'Sullivan MJ, Margolis KL, Ockene JK, Phillips L, Pottern L, Prentice RL, et al. Calcium plus vitamin D supplementation and the risk of colorectal cancer. N Engl J Med. 2006;354(7):684-96.

69. Bischoff-Ferrari HA, Giovannucci E, Willett WC, Dietrich T, Dawson-Hughes B. Estimation of optimal serum concentrations of 25-hydroxyvitamin D for multiple health outcomes. Am J Clin Nutr. 2006;84(1):18-28.

70. • Manson JE, Bassuk SS, Lee IM, Cook NR, Albert MA, Gordon D, Zaharris E, Macfadyen JG, Danielson E, Lin J, Zhang SM, et al. The VITamin D and OmegA-3 TriaL (VITAL): rationale and design of a large randomized controlled trial of vitamin D and marine omega-3 fatty acid supplements for the primary prevention of cancer and cardiovascular disease. Contemp Clin Trials. 2011;33(1):159-71. This article describes the rationale and the study design of VITAL, the first large-scale randomized clinical trial of vitamin $D$ for the primary prevention of cancer and CVD.

71. Hathcock JN, Shao A, Vieth R, Heaney R. Risk assessment for vitamin D. Am J Clin Nutr. 2007;85(1):6-18. 